\title{
Psychometric properties of the self-report version of the strengths and difficulties questionnaire in the Ecuadorian context: an evaluation of four models
}

Paúl Arias-Medina(1)

The authors have retracted this article because the Strengths and Difficulties Questlonna has been modified without permission from the copyright holder youth in mind. The content of the article is no onger available owing to this breach.

All authors agree with this retraction.

Correspondence: paul.arias@ucuenca.edu.ec

Faculty of Psychology, University of Cuenca, Cuenca, Ecuador

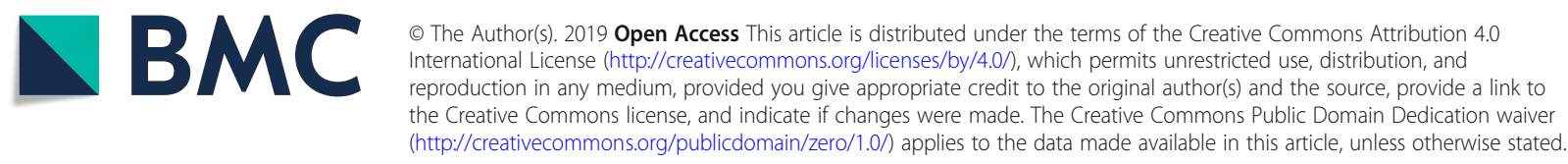




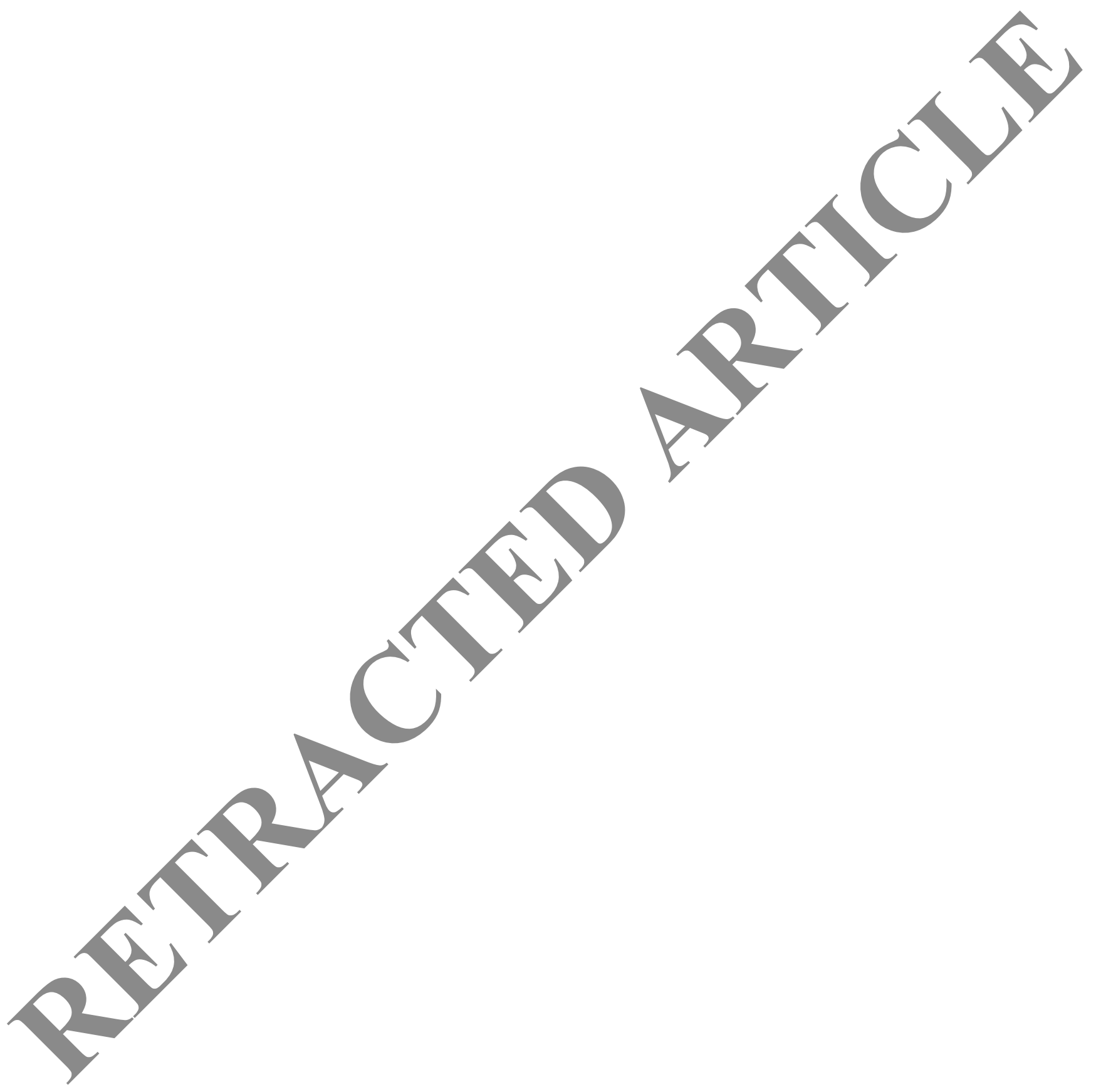




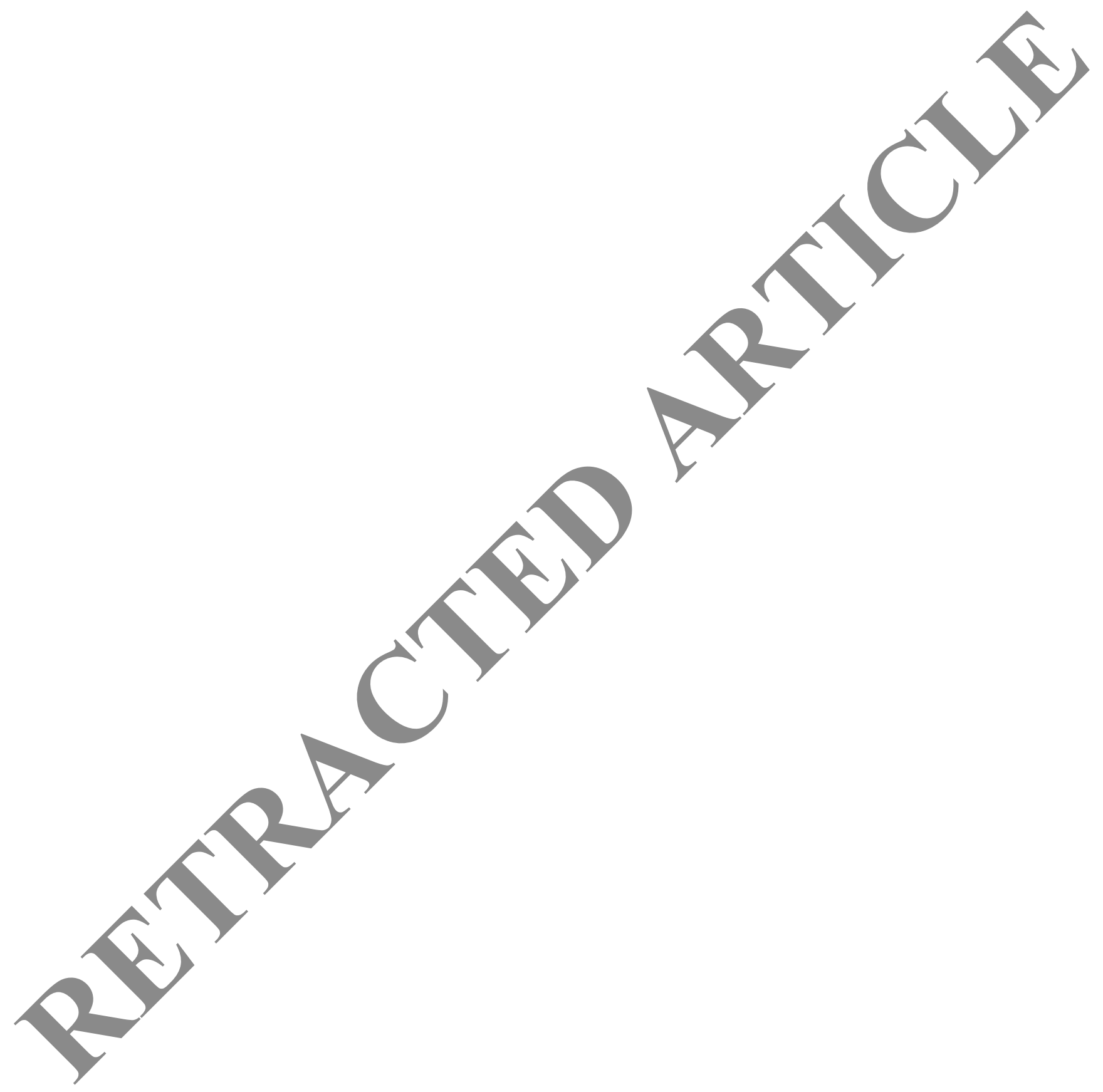




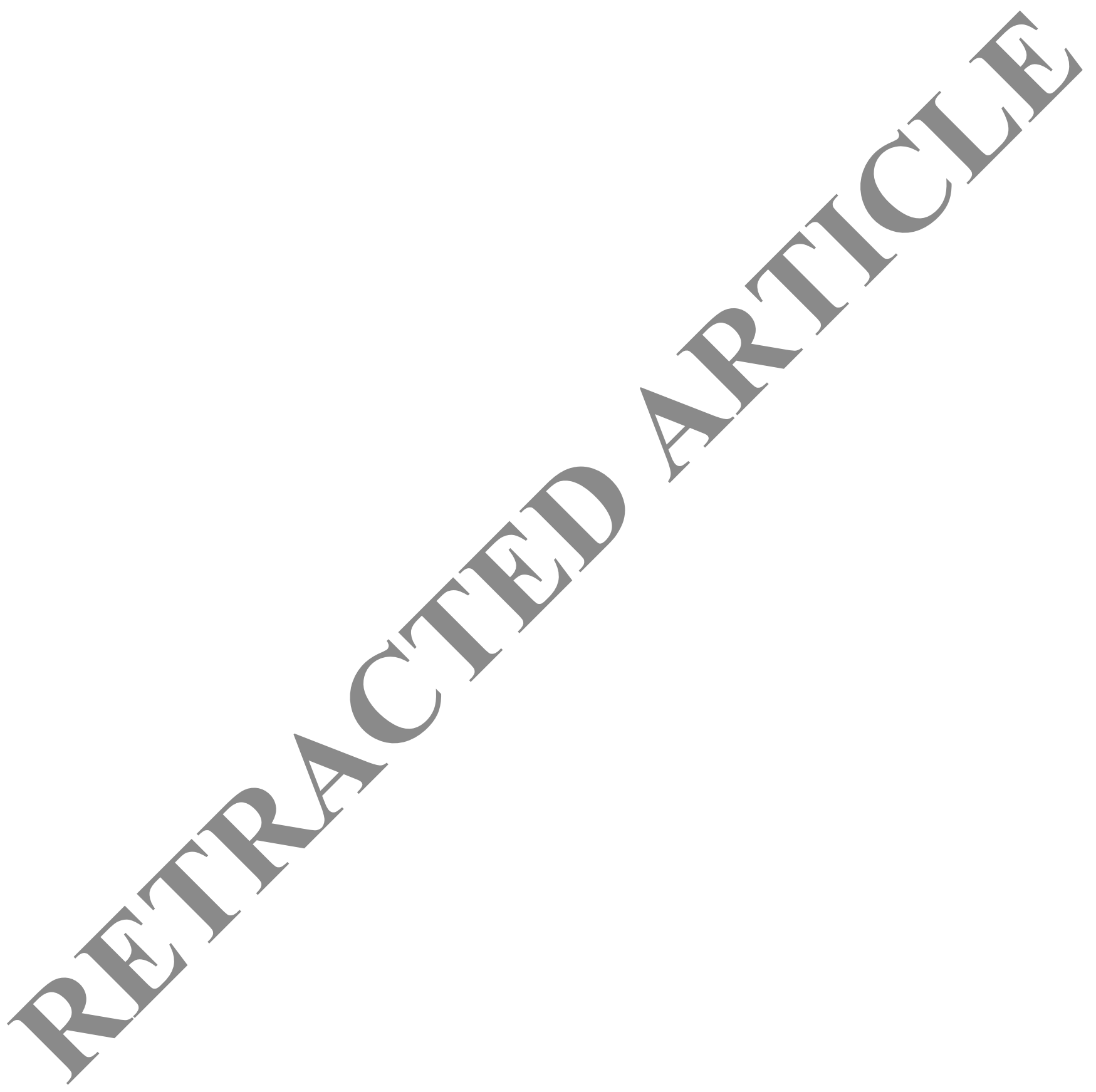




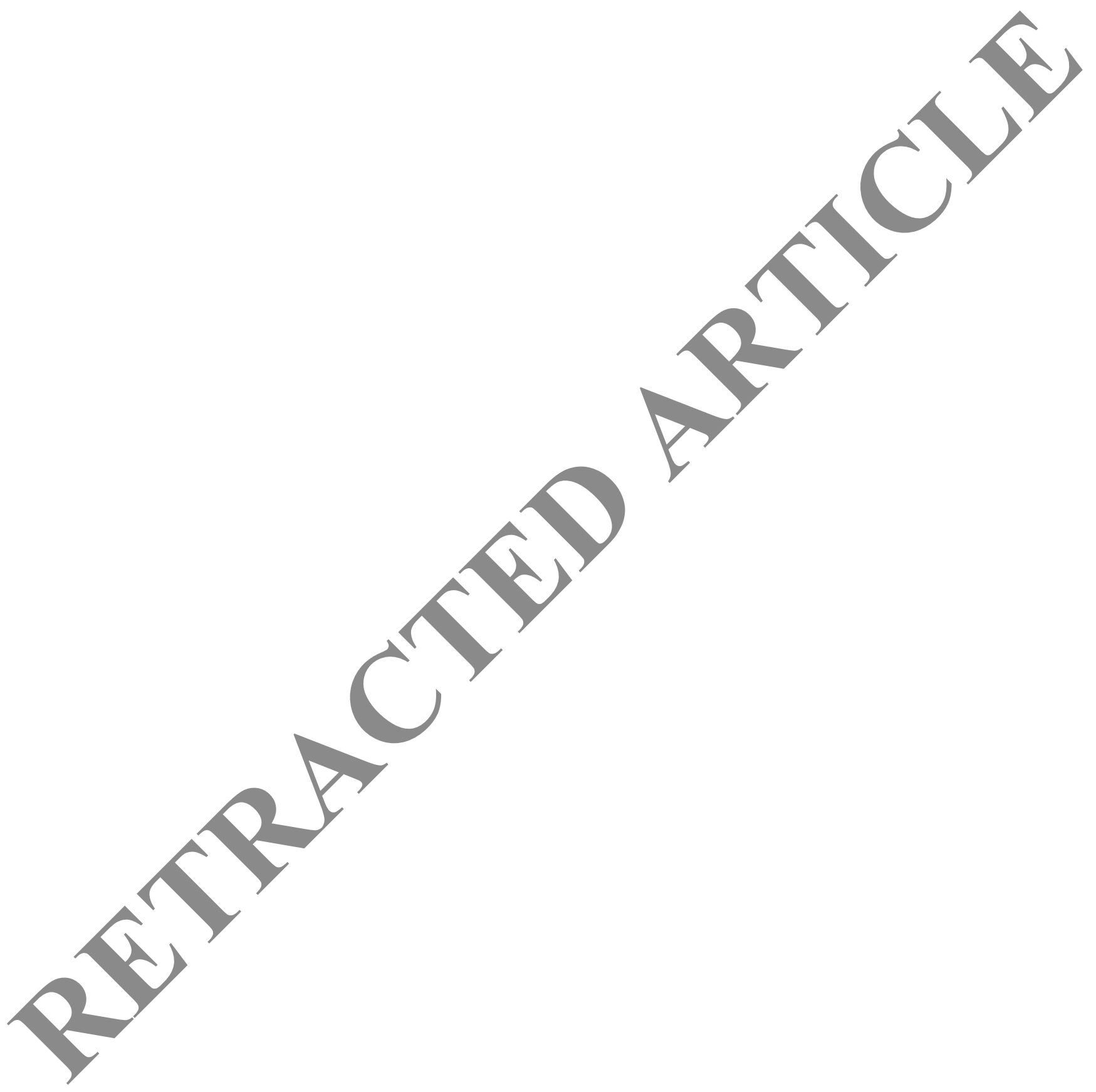




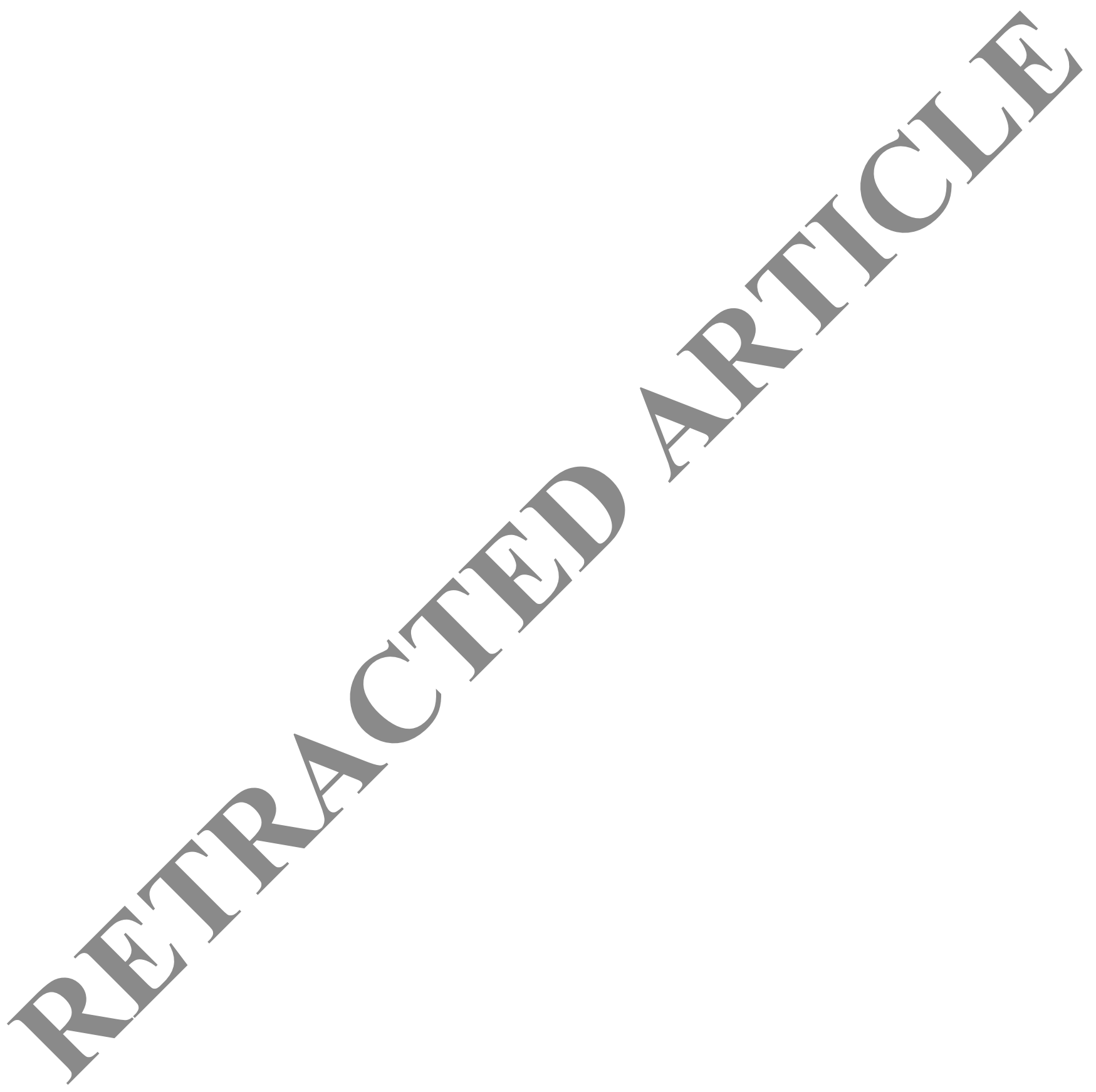




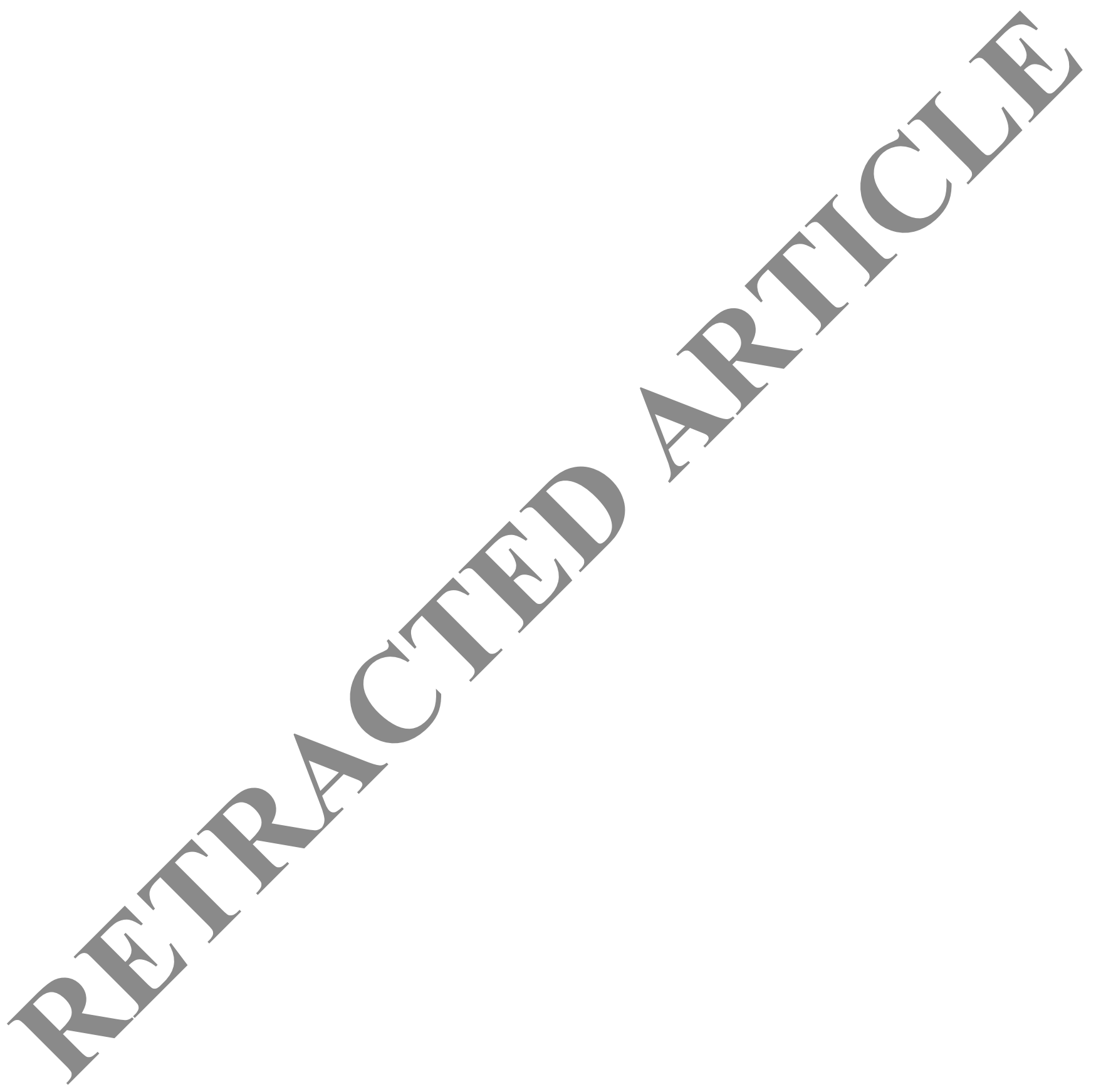




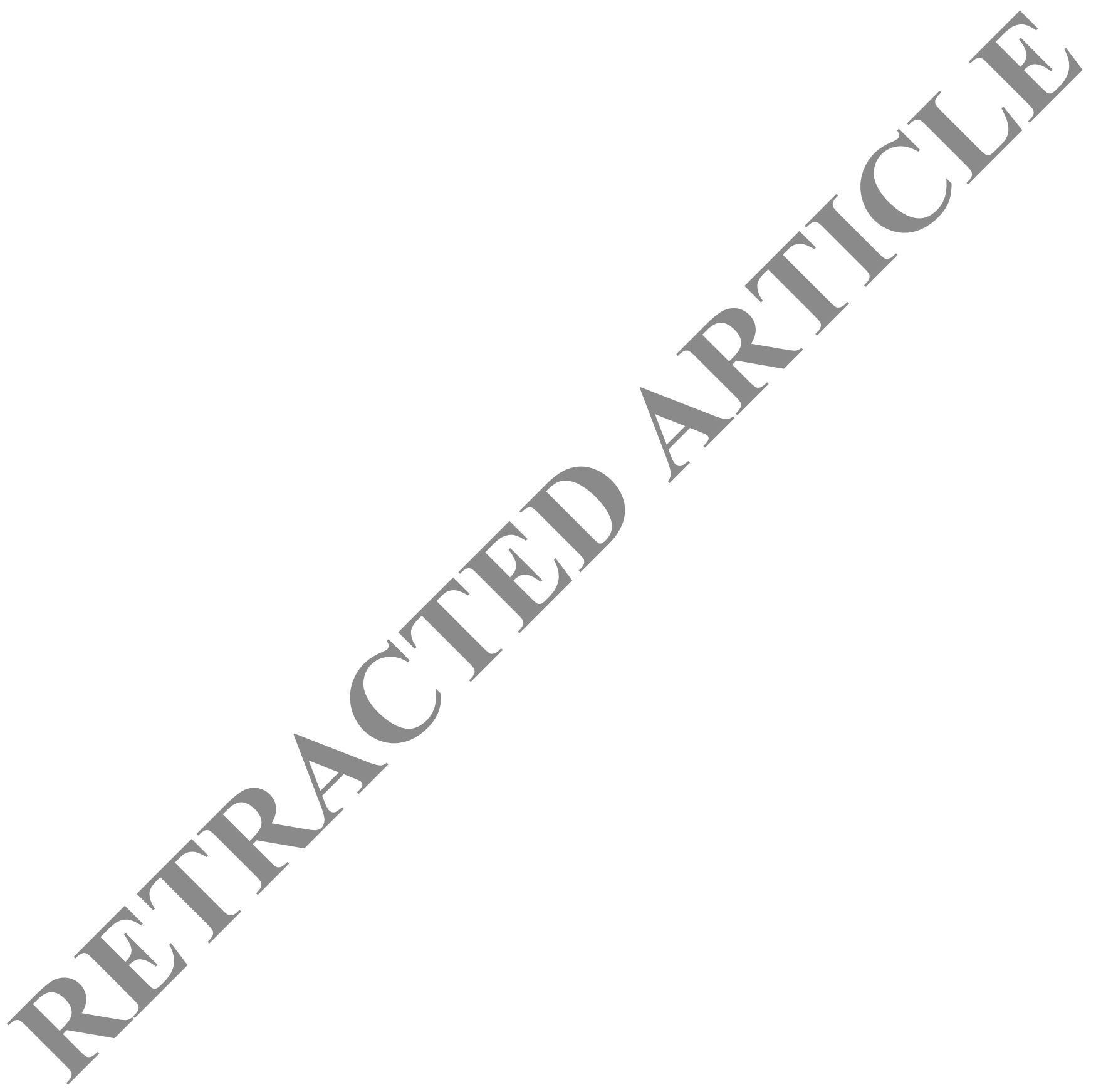




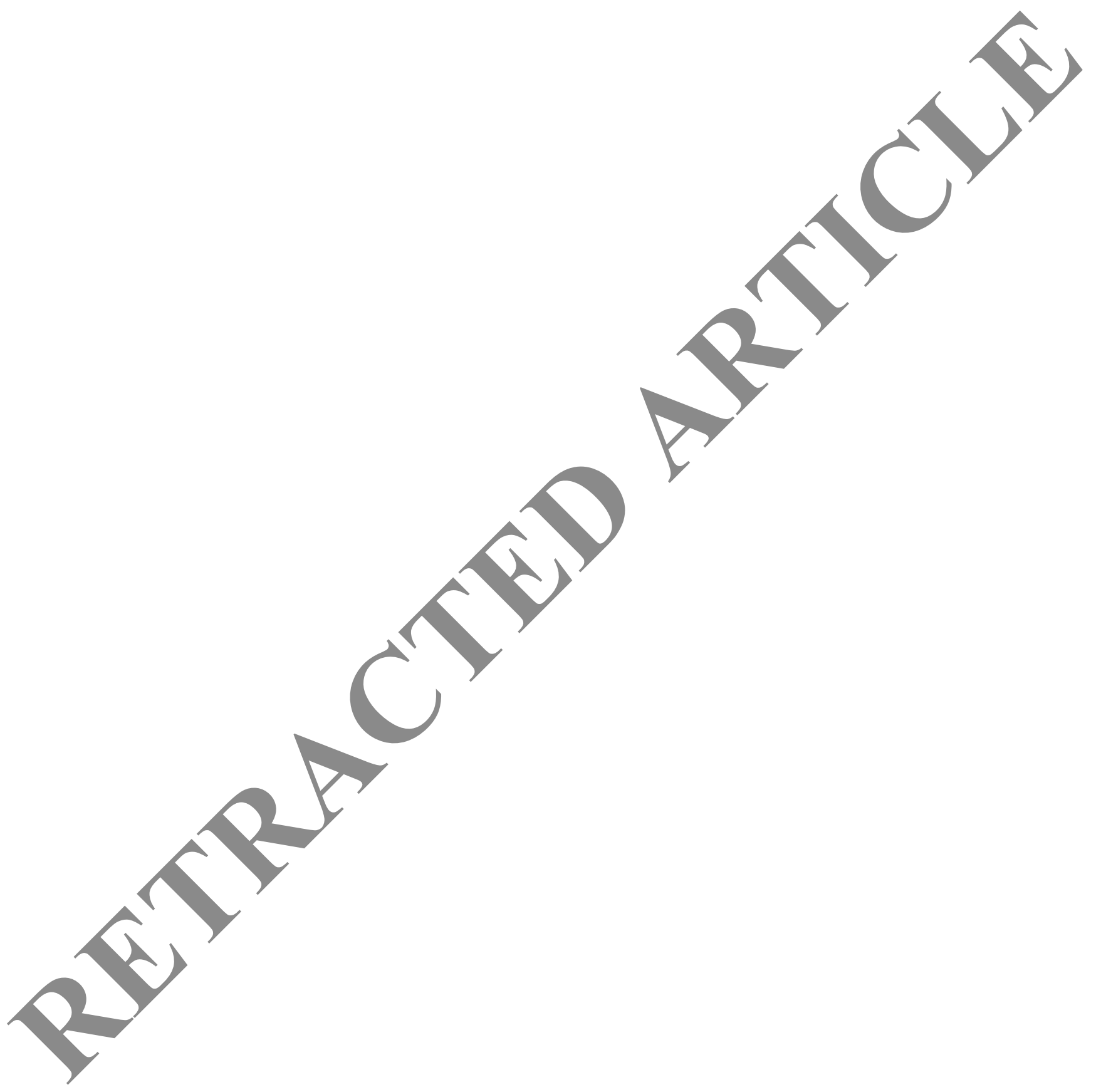




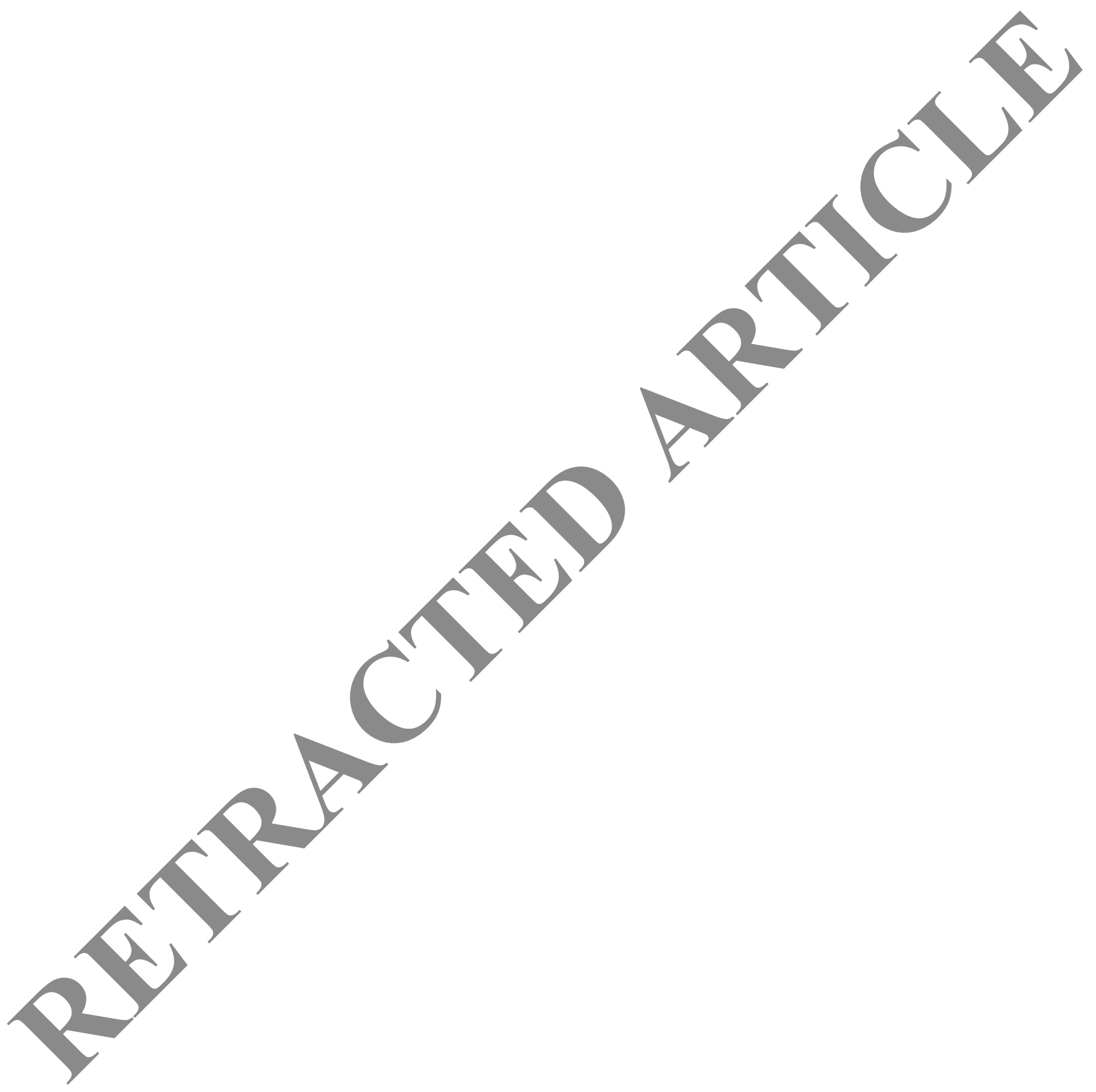




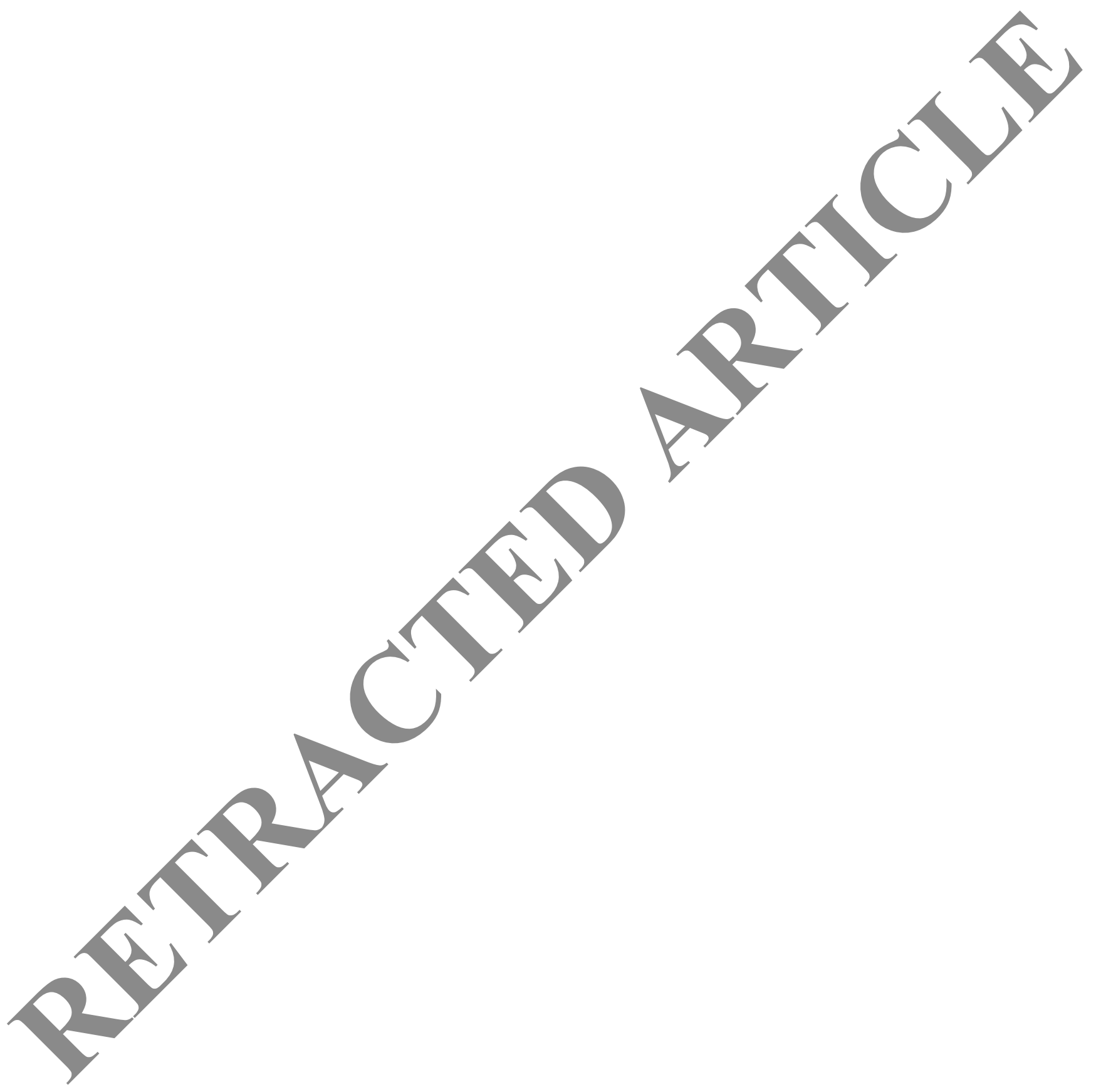

